\title{
Kinetic Probes of the Origin of Activity in MOF-Based C-H Oxidation Catalysts
}

\author{
Aishanee Sur, Nicholas B. Jernigan, and David C. Powers* \\ $\dagger$ Department of Chemistry, Texas A\&M University, College Station, TX 77843, USA \\ *powers@chem.tamu.edu
}

\begin{abstract}
The development of homogeneous catalysis is enabled by the availability of a rich toolkit of kinetics experiments, such as the Hg-drop test, that differentiate catalytic activity at ligandsupported metal complexes from potential heterogeneous catalysts derived from decomposition of molecular species. Metal-organic frameworks (MOFs) have garnered significant attention as platforms for catalysis at site-isolated, interstitial catalyst sights. Unlike homogeneous catalysis, relatively few strategies have been advanced to evaluate the origin of catalytic activity in MOFpromoted reactions. Many of the MOFs that have been examined as potential catalysts are comprised of molecular constituents that represent viable catalysts in the absence of the extended MOF lattice, and thus interfacial sites and leached homogeneous species represent potential sources of catalyst activity. Here, we demonstrate that analysis of deuterium kinetic isotope effects (KIEs) and olefin epoxidation diastereoselectivity provides direct probes of the origin of catalytic activity in MOF-promoted oxidation reactions. These analyses support direct involvement of lattice-based $\mathrm{Fe}$ sites in the turnover-limiting step of $\mathrm{C}-\mathrm{H}$ activation with Fe-MOF-74-based materials (i.e., the MOF functions as a bona fide catalyst) and evidence that $\mathrm{Cu}_{2}$-based MOF MIL$125-\mathrm{Cu}_{2} \mathrm{O}_{2}$ functions as a solid-state initiator for solution-phase oxidation chemistry and is not involved in the turnover limiting step (i.e., the MOF does not function as a catalyst). We anticipate that the simple experiments described here will provide a valuable tool for clarifying the role of MOFs in $\mathrm{C}-\mathrm{H}$ oxidation reactions.
\end{abstract}


The discovery and development of selective catalytic methods for the oxidation of organic small molecules promises to streamline the preparation of functional molecules that span the organic chemical value chain. ${ }^{1}$ Metal-organic frameworks (MOFs), which feature geometrically well-defined transition metal ion sites confined within extended porous lattices, have garnered significant attention as synthetically modular platforms for heterogeneous catalysis that can be optimized through systematic synthetic logic. ${ }^{2}$ The co-localization of lattice-bound metal ions and pore-confined substrates within MOF interstices has inspired analogies between MOF-based catalysts and enzymatic systems that accomplish challenging small molecule activation and substrate functionalization reactions within nanoporous enzyme active sites. ${ }^{3}$ Rational design and optimization of MOF catalysts requires 1) experimental correlation of material structure with catalyst activity (i.e. turnover frequency) and selectivity, and 2) a clear understanding of the structural origin of the observed catalytic activity. Because many MOF catalysts are comprised of molecular building blocks that represent viable catalysts in the absence of the extended MOF lattice, observed catalytic activity could potentially originate from interstitial catalyst sites, solvent-exposed interfacial sites, or at soluble molecular species liberated by leaching. While substantial work has been pursued to develop highly active MOF catalysts, relatively less effort has been aimed at developing robust experimental methods to evaluate the origin of the catalytic activity in these materials. ${ }^{4}$

Differentiating whether catalytic activity arises from homogeneous molecular species or from potential heterogeneous catalysts generated by in situ decomposition of those molecular precursors is a classic challenge in organometallic catalysis. ${ }^{5}$ For example, both ligand-supported molecular Pd complexes and nanoparticulate $\operatorname{Pd}(0)$, generated by decomposition of molecular species, can 
display activity in Pd-catalyzed cross-coupling reactions. ${ }^{6}$ The Hg-drop test, which is predicated on selective amalgamation (and thus poisoning) of (nano)particulate $\operatorname{Pd}(0)$, is a classic experimental strategy designed to assess the origin of catalyst activity in these reactions: ${ }^{78}$ If addition of $\operatorname{Hg}(0)$ results in no impact on the rate of the Pd-catalyzed reaction, it is assumed that ligand-supported molecular complexes are the source of the observed catalytic activity; in contrast, if addition of $\operatorname{Hg}(0)$ suppresses the reaction rate, catalyst activity may be attributed to particulate $\operatorname{Pd}(0)$. Beyond the Hg-drop test, a rich toolkit of experimental strategies based on selective catalyst poisons and reaction kinetics analysis have been developed to evaluate the origin of observed catalytic activity in both homo- and heterogeneous organometallic catalysis. ${ }^{5}$



Figure 1. Identifying the origin of catalytic activity in MOF-promoted $\mathrm{C}-\mathrm{H}$ oxidation - either at lattice-supported interstitial metal sites, at surface-exposed interfacial sites, or via potential solution-phase processes - is challenging. Here we advance analysis of deuterium kinetic isotope effects (KIEs) and olefin epoxidation diastereoselectivity as kinetic probes to differentiate lattice-confined and solution-phase oxidation activity.

Because the constituent monomers that comprise MOF lattices are often potentially viable catalysts in the absence of the extended MOF lattice, evaluating the origin of apparent catalytic activity — interstitial, interfacial, and potential solution-phase active species — in MOF-promoted reactions is challenging. While a number of experimental strategies that rely on synthetic catalyst modification have been advanced, such as the synthesis and evaluation of core-shell 
heterostructures that do not display potential interfacial catalyst sites, few in operando methods are available to evaluate the origin of catalytic activity of MOFs. ${ }^{4} \mathrm{We}$ have been interested in developing simple in operando kinetic probes to evaluate the origins of, and barriers to, MOF catalysis. Kinetic isotope effects (KIEs) provide a direct probe of the structure of the turnoverlimiting step in catalysis and we have previously utilized the relative magnitudes of intra- and intermolecular KIEs to evaluate substrate mobility during interstitial group-transfer chemistry. ${ }^{9}$ Here we advance simple experimental methods based on 1) KIE analysis and 2) olefin functionalization diastereoselectivity, which provides a kinetic probe of oxidation catalysis, to evaluate the role of MOFs in substrate oxidation reactions. Application of these methods to known MOF-catalyzed $\mathrm{C}-\mathrm{H}$ oxidation reactions indicates that whereas MOF-supported reactive intermediates are intimately involved in the substrate functionalization event for Fe-MOF-74 materials, MIL-125- $\mathrm{Cu}_{2} \mathrm{O}_{2}$ serves as initiator for solution-phase oxidation chemistry and is not involved in substrate functionalization as a catalyst. The described experiments provide simple tools to evaluate the origin of activity of MOF-catalyzed $\mathrm{C}-\mathrm{H}$ oxidation and will enable rational optimization of MOF based catalysts.

In 2021, Lin et al. reported the post-synthetic metalation of MIL-125 with $\mathrm{Cu}(\mathrm{I})$ to generate a material featuring $\mathrm{Cu}_{2}$ sites and the subsequent aerobic oxidation of these sites to afford MIL-125$\mathrm{Cu}_{2} \mathrm{O}_{2} \cdot{ }^{10}$ Inspired by the $\mathrm{C}-\mathrm{H}$ hydroxylation activity of aerobically generated $\mathrm{Cu}_{2} \mathrm{O}_{2}$ sites in enzymatic catalysts, such as particulate methane monooxygenase (pMMO),${ }^{11}$ and heterogeneous catalysts, such as $\mathrm{Cu}$-doped ZSM-5, ${ }^{12} \mathrm{MIL}-125-\mathrm{Cu}_{2} \mathrm{O}_{2}$ was targeted as a catalyst for aerobic oxidation catalysis. In the presence of $\mathrm{O}_{2}$ and isobutyraldehyde, which is added as the obligate coreductant to manage the four-electron reduction inventory of $\mathrm{O}_{2}, \mathrm{MIL}-125-\mathrm{Cu}_{2} \mathrm{O}_{2}$ effects the aerobic oxygenation of $\mathrm{C}-\mathrm{H}$ bonds, epoxidation of olefins, and oxidation of sulfides. ${ }^{10}$ Based on 
our ongoing interest in utilizing the reactive intermediates generated in aldehyde autoxidation to accomplish aerobic oxidation chemistry, ${ }^{13}$ we were attracted to this report as a potential example of autoxidation intermediates being intercepted for the synthesis of reactive metal-based oxidants relevant to $\mathrm{C}-\mathrm{H}$ oxidation catalysis.

We initiated our experimental work by examining the isobutyraldehyde-promoted aerobic oxidation of tetralin (1) to 3,4-dihydronaphthalen-1(2H)-one (2). In the absence of MIL-125$\mathrm{Cu}_{2} \mathrm{O}_{2}$ (characterized by powder X-ray diffraction (PXRD), gas adsorption analysis, and solid-state UV-vis spectroscopy, see Figures S1-S3), no C-H oxidation was observed (Table 1, Entry 1). In the presence of MIL-125- $\mathrm{Cu}_{2} \mathrm{O}_{2}$, we observed significant variability in the course of substrate oxidation: In some experiments, oxidation of $\mathbf{1}$ to $\mathbf{2}$ began promptly while in others, significant induction periods were observed. The yield of 2 varied from $30-68 \%$ in reactions carried out in the presence of MIL-125- $\mathrm{Cu}_{2} \mathrm{O}_{2}$. Induction periods are common in autoxidation chemistry ${ }^{14}$ and motivated us to further examine the role of $\mathrm{MIL}-125-\mathrm{Cu}_{2} \mathrm{O}_{2}$ in substrate functionalization. We reasoned that analysis of the KIEs for substrate oxidation would provide a direct reporter of the role (or lack thereof) of $\mathrm{MIL}-125-\mathrm{Cu}_{2} \mathrm{O}_{2}$ in the $\mathrm{C}-\mathrm{H}$ bond cleavage involved in oxygenation. We measured both intra- and intermolecular KIEs (see Section D.1, Supporting Information), using either $d_{2}-\mathbf{1}$ or a mixture of $\mathbf{1}$ and $d_{4}-\mathbf{1}$, respectively, for the aerobic oxidation of $\mathbf{1}$ to $\mathbf{2}$ (Table 1 , Entry 2). Exposure of a 1,2-dichloroethane (DCE) solution of $d_{2}-1$ to $\mathrm{MIL}-125-\mathrm{Cu}_{2} \mathrm{O}_{2}(0.5 \mathrm{~mol} \%)$, isobutyraldehyde, and $\mathrm{O}_{2}$ resulted in a mixture of $d_{0}-2$ and $d_{2}-2$. Analysis of the ratio of these isotopologues by both APCI-MS and ${ }^{1} \mathrm{H}$ NMR spectrum provided an intramolecular $k_{\mathrm{H}} / k_{\mathrm{D}}$ $=10.4(7)$. Oxidation of a 1:1 mixture of $d_{0}-\mathbf{1}$ and $d_{4}-\mathbf{1} d_{2}-\mathbf{1}$ under analogous conditions resulted in a mixture of $d_{0-2}$ and $d_{2}-\mathbf{2}$, with an intermolecular $k_{\mathrm{H}} / k_{\mathrm{D}}=10.2(5)$. 
Table 1. Summary of kinetic isotope effects for aldehyde-promoted aerobic $\mathrm{C}-\mathrm{H}$ oxygenation in the presence of MIL$125-\mathrm{Cu}_{2} \mathrm{O}_{2}$ and various divalent transition metal salts.

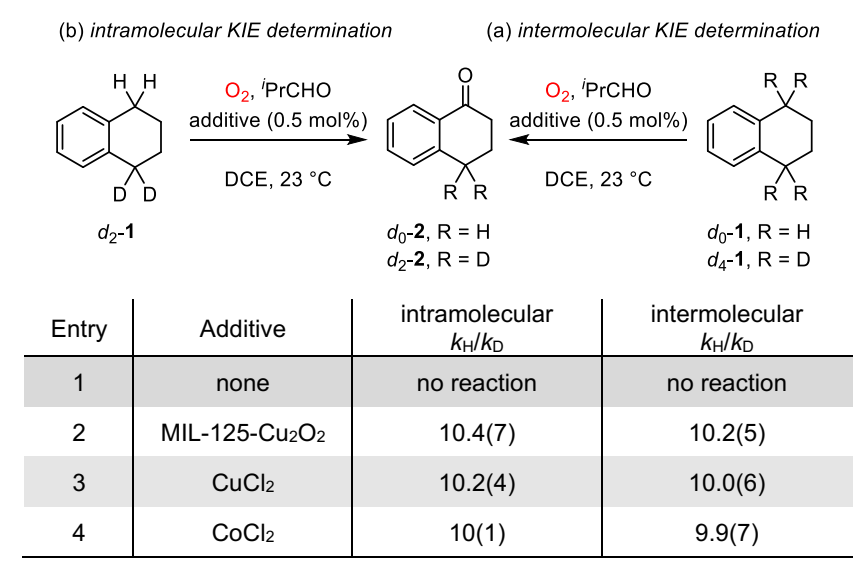

Given previous reports that uncatalyzed $\mathrm{C}-\mathrm{H}$ oxygenation reactions can be effected by aldehyde autoxidation intermediates (e.g., aerobically generated peroxy radicals) ${ }^{14,15,16}$ and typically display large primary KIEs (i.e., 9-19) ${ }^{17}$ we were interested in comparing the measured KIEs for the oxidation of 1 in the presence of MIL-125- $-\mathrm{Cu}_{2} \mathrm{O}_{2}$ with those obtained for oxidation of 1 by reactive species generated during autoxidation. Addition of $\mathrm{CuCl}_{2}$, which is frequently employed as autoxidation initiator, ${ }^{18}$ resulted in the oxidation of $\mathbf{1}$ to $\mathbf{2}$ in $83 \%$ yield. Using the same labeled tetrahydronaphthalene as before (i.e., either $d_{2} \mathbf{- 1}$ or a mixture of $d_{0} \mathbf{- 1}$ and $d_{4} \mathbf{- 1}$ ), we determined inter- and intramolecular $k_{\mathrm{H}} / k_{\mathrm{D}}=10.0(6)$ and 10.2(4), respectively (Table 1, Entry 3 ). The identity of the initiator had no impact on the determined KIEs: Replacement of $\mathrm{CuCl}_{2}$ with $\mathrm{CoCl}_{2}$ resulted in oxidation of 1 to afford 2 with intra- and intermolecular $k_{\mathrm{H}} / k_{\mathrm{D}}=10(1)$ and 9.9(7), respectively (Table 1, Entry 4). The identical KIEs obtained using MIL-125- $\mathrm{Cu}_{2} \mathrm{O}_{2}, \mathrm{CoCl}_{2}$, and $\mathrm{Cu}_{2} \mathrm{Cl}_{2}$ suggest that each of these metal-based additives serves to initiate autoxidation but are not involved in the turnover limiting transition state.

Similar to the analysis of KIEs, olefin epoxidation diastereoselectivity provide a direct probe of the structure of the selectivity determining step(s) in catalysis. ${ }^{19}$ To gain further insight 
regarding the role of MIL-125- $\mathrm{Cu}_{2} \mathrm{O}_{2}$ in promoting substrate oxidation chemistry, we evaluated the diastereoselectivity of epoxidation of b-methyl styrene (3a) or 2-hexene (3b) in the presence of MIL-125- $\mathrm{Cu}_{2} \mathrm{O}_{2}, \mathrm{CuCl}_{2}$, or $\mathrm{CoCl}_{2}$ (see Section D.2, Supporting Information). The results of these experiments are summarized in Table 2. These data demonstrate that regardless of the initiator employed, epoxidation of trans-b-methyl styrene (trans-3a) resulted in almost exclusively trans-4a whereas epoxidation of trans-2-hexene (trans-3b) resulted in a 9:1 mixture of trans:cis4b. Similarly, epoxidation of cis-olefins proceeded with initiator-independent diastereoseletivity: Epoxidation of cis-3a resulted in a $\sim 2: 8$ mixture of cis- and trans-4a whereas epoxidation of cis$\mathbf{3 b}$ resulted in a $\sim 5.5: 4.5$ mixture of cis- and trans $-\mathbf{4 b}$. These data are consistent with the lack of stereospecificity typical of epoxidation by peroxy radical intermediates. It is important to highlight that it is critical to examine the diastereoselectivity of both cis and trans olefins because transolefins undergo epoxidation with high diastereoselectivity for trans-epoxide and thus do not represent sensitive stereochemical probes. Valentine and Finke previously utilized olefin oxidation diastereoslectivity to demonstrate that the Mukaiyama reaction, in which olefins are epoxidized under aldehyde autoxidation conditions in the presence of metal porphyrin additives, does not involve metal oxo intermediates but instead arises from direct reaction between olefins and autoxidation intermediates. ${ }^{20}$ Further evidence for the critical role of autoxidation intermediates in substrate functionalization is the observation of $\sim 10 \%$ allylic oxidation products, which are typically observed byproducts of autoxidation chemistry. 
Table 2. Summary of olefin epoxidation diastereoselectivity for aldehyde-promoted aerobic $\mathrm{C}-\mathrm{H}$ oxygenation in the presence of MIL-125- $\mathrm{Cu}_{2} \mathrm{O}_{2}$ and various divalent transition metal salts.

\begin{tabular}{|c|c|c|c|}
\hline \multicolumn{2}{|c|}{ 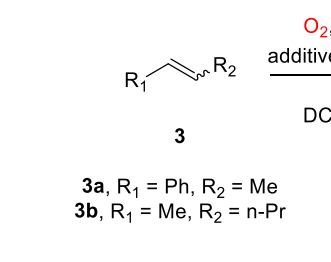 } & cis. & $\begin{array}{c}\mathrm{R}_{1}{ }^{\prime \prime} \sum_{\mathrm{R}_{2}}^{\mathrm{O}} \\
\text { trans-4}\end{array}$ \\
\hline \multirow{2}{*}{ substrate } & \multicolumn{3}{|c|}{ Additive (cis-4: trans-4) } \\
\hline & MIL-125- $\mathrm{Cu}_{2} \mathrm{O}_{2}$ & $\mathrm{CoCl}_{2}$ & $\mathrm{CuCl}_{2}$ \\
\hline cis-3a & $2: 8$ & $1.8: 8.2$ & $2: 8$ \\
\hline trans-3a & $0.7: 9.3$ & $0.3: 9.7$ & $0.6: 9.4$ \\
\hline cis-3b & 5.6:4.4 & $5.2: 4.8$ & $6.3: 3.7$ \\
\hline trans-3b & $1.1: 8.9$ & $0.9: 9.1$ & $1.1: 8.9$ \\
\hline
\end{tabular}

The combination of deuterium KIE data, which indicate that the rate-determining transition state of $\mathrm{C}-\mathrm{H}$ oxidation does not include participation of the transition metal additive, and olefin epoxidation diastereoselectivities, which indicate that the transition metal additives do not impact epoxidation diastereoselectivity, demonstrates that $\mathrm{MIL}-125-\mathrm{Cu}_{2} \mathrm{O}_{2}$ is not a $\mathrm{C}-\mathrm{H}$ oxidation catalyst but instead serves as a heterogeneous initiator of aldehyde autoxidation. Subsequent substrate functionalization is accomplished by solution-phase, reactive autoxidation intermediates. While it is possible that MIL-125- $\mathrm{Cu}_{2}$-supported species are capable of effecting the observed substrate functionalization reactions, the available in operando kinetic data indicate that they are not responsible for the apparent $\mathrm{C}-\mathrm{H}$ oxidation catalysis.

Following our study of the origin of activity in MIL-125- $\mathrm{Cu}_{2} \mathrm{O}_{2}$ promoted aerobic oxidation, we extended the analysis of deuterium KIEs and olefin oxidation diastereoselectivity to oxidation catalysis promoted by an isoreticular family of Fe-MOF-74 analogues (characterized by PXRD and gas adsorption analysis, see Figures S4-S7). These materials, which are comprised on fivecoordinate, square pyramidal Fe(II) sites supported in an all-oxygen ligand field, have been advanced by Long and co-workers as a platform for aliphatic $\mathrm{C}-\mathrm{H}$ oxidation at lattice-confined, 
high-valent $\mathrm{Fe}$ oxo intermediates. ${ }^{21}$ Based on previous reports that restricted diffusion of cyclohexane into $\mathrm{Fe}_{2}$ (dobdc) (Fe-MOF-74; pore diameter is $8 \AA$ ) prevented efficient oxidation chemistry from being achieved, we initiated our studies with pore-expanded analogue $\mathrm{Fe}_{2}\left(\operatorname{dotpdc}^{\mathrm{F}}\right)$, which features significant larger interstitial voids (pore diameter is $25 \AA$ ).

Exposure of $\mathrm{Fe}\left(\operatorname{dotpdc}^{\mathrm{F}}\right) \cdot 2 \mathrm{CH}_{3} \mathrm{CN}$ to a $\mathrm{CD}_{3} \mathrm{CN}$ solution of $\mathbf{1}$ and 2-tert-butylsulfonyl iodosylbenzene (6) resulted in the evolution of 1,2,3,4-tetrahydronaphthalen-1-ol (5) (Table 3), which was characterized by ${ }^{1} \mathrm{H}$ NMR and APCI-MS analysis, ${ }^{22}$ with a turnover number (TON) of 3.0(1). There is no background reaction in the absence of $\mathrm{Fe}_{2}\left(\operatorname{dotpdc}^{\mathrm{F}}\right)$ (Table 3, Entry 1). Oxidation of $d_{2}-\mathbf{1}$ with 6 in the presence of $\mathrm{Fe}\left(\operatorname{dotpdc}^{\mathrm{F}}\right) \cdot 2 \mathrm{CH}_{3} \mathrm{CN}$ resulted in a mixture of $d_{1}$ - and $d_{2}-5$ with an intramolecular $k_{\mathrm{H}} / k_{\mathrm{D}}=5.2(3)$ (Table 3, Entry 2) (see Section E.1, Supporting Information). Oxidation of a mixture of $d_{0}-\mathbf{1}$ and $d_{4}-\mathbf{1}$ afforded a mixture of $d_{0}$ - and $d_{3}-5$ with an intermolecular $k_{\mathrm{H}} / k_{\mathrm{D}}=4.4(2)$. Two comparisons provide context for these KIEs: First, oxidation of 1 to $\mathbf{5}$ with $\mathrm{Fe}(\mathrm{OTf})_{2}$ as catalyst proceeds with intra- and intermolecular KIEs of 3.2(3) and 2.9(1), respectively (Table 3, Entry 3), which are significantly lower than those measured for $\mathrm{Fe}_{2}\left(\operatorname{dotpdc}^{\mathrm{F}}\right)$. This observation suggests that leached $\mathrm{Fe}(\mathrm{II})$ ions are not responsible for the observed catalytic activity. Second, use of $\mathrm{Fe}_{2}(\mathrm{dobpdc})($ pore size $=19 \AA)$ in place of $\mathrm{Fe}_{2}\left(\operatorname{dotpdc}^{\mathrm{F}}\right)$ gives rise to the same intramolecular $k_{\mathrm{H}} / k_{\mathrm{D}}=5.2(1)$ and a slightly smaller intermolecular KIE (3.9(1)) (Table 3, Entry 4). We hypothesize that the differences observed between intra- and intermolecular KIEs in these systems may result from confinement effects at interstitial catalyst sites. Whereas intramolecular KIEs report on the selectivity-determining step of catalysis, intermolecular KIEs report on the rate-determining step. ${ }^{23}$ Previous studies have demonstrated that confinement can give rise to lower-than-expected deuterium KIEs. Finally, use of Fe-MOF-74 $\left(\mathrm{Fe}_{2}(\mathrm{dobdc})\right)$ results in insufficient conversion of $\mathbf{1}$ to $\mathbf{5}$ to accurately determine $k_{\mathrm{H}} / k_{\mathrm{D}}$ values. 
Table 3. Summary of kinetic isotope effects for $\mathrm{C}-\mathrm{H}$ hydroxylation catalyzed by a reticular family of Fe-MOF-74based MOFs.

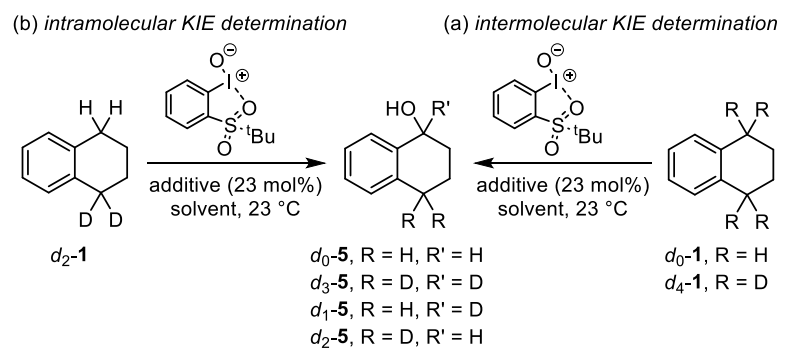

\begin{tabular}{c|c|c|c} 
Entry & Additive & $\begin{array}{c}\text { intramolecular } \\
\boldsymbol{k}_{\mathbf{H}} / \boldsymbol{k}_{\mathbf{D}}\end{array}$ & $\begin{array}{c}\text { intermolecular } \\
\boldsymbol{k}_{\mathbf{H}} / \boldsymbol{k}_{\mathbf{D}}\end{array}$ \\
\hline 1 & none & no reaction & no reaction \\
2 & $\mathrm{Fe}_{2}\left(\right.$ dotpdc $\left.^{\mathrm{F}}\right) \cdot 2 \mathrm{CH}_{3} \mathrm{CN}$ & $5.2(3)$ & $4.4(2)$ \\
3 & $\mathrm{Fe}(\mathrm{OTf})_{2}$ & $3.2(3)$ & $2.9(1)$ \\
4 & $\mathrm{Fe}_{2}$ (dobpdc) $\cdot 2 \mathrm{CH}_{3} \mathrm{CN}$ & $5.3(1)$ & $3.9(1)$ \\
\hline
\end{tabular}

Further support for the intimate role of lattice-supported Fe oxo species in substrate functionalization was obtained by examining the diastereoselectivity of olefin epoxidation catalyzed by these materials (Table 4) (see Section E.2, Supporting Information). Epoxidation of trans-2-hexene (trans-3b) proceeded to give 99:1 trans:cis-2-hexene oxide (4b) with $\mathrm{Fe}_{2}\left(\operatorname{dotpdc}^{\mathrm{F}}\right)$ and $\mathrm{Fe}_{2}(\mathrm{dobpdc})$ as catalyst (23 mol\%) (Table 4, Entry 1). Similarly high levels of stereoselectivity were observed for epoxidation of trans-b-methylstyrene (trans-3a) (Table 4, Entry 2). Epoxidation with $\mathrm{Fe}(\mathrm{OTf})_{2}$ in place of the Fe-based MOFs also promoted epoxidation with high levels of transselectivity. In contrast, while oxidation of either cis-2-hexene (cis-3b) (Table 4, Entry 3) or cis-bmethylstyrene (cis-3a) (Table 4, Entry 4) resulted in preferential formation of cis-2-hexene oxide (cis-4b) with either of the MOF catalysts, epoxidation in the presence of $\mathrm{Fe}(\mathrm{OTf})_{2}$ is poorly stereoselective. For all of the olefin starting materials, there is no background epoxidation in the absence of Fe additives. 
Table 4. Summary of olefin epoxidation diastereoselectivity for Fe-catalyzed olefin epoxidation chemistry.

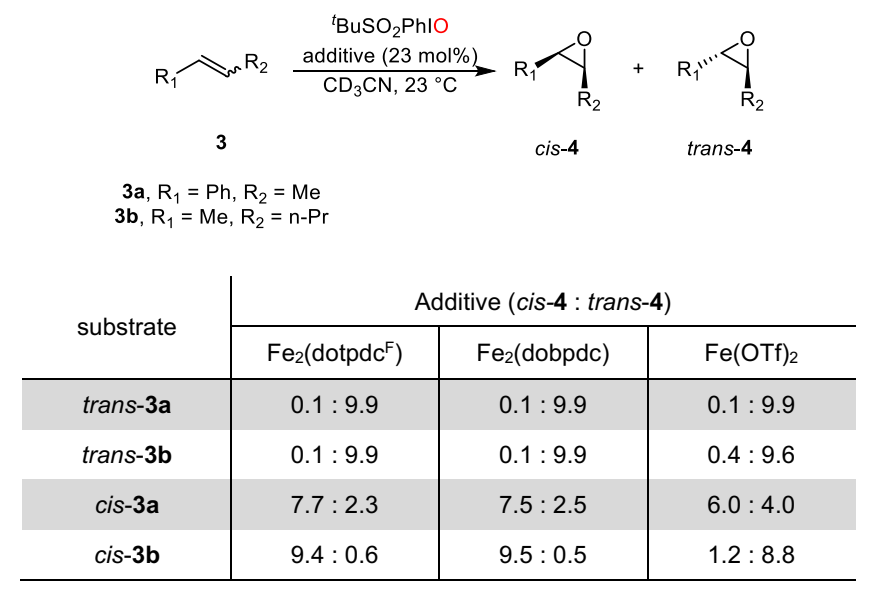

Taken together, the magnitudes of deuterium KIEs compared with those obtained with simple $\mathrm{Fe}(\mathrm{II})$ additives and a as a function of pore size, combined with the observed highly stereospecific olefin epoxidation belie an intimate role for lattice-confined Fe sites in the turnover-limiting and selectivity-determining transition states of substrate functionalization.

The development of designer porous catalysts promises to provide opportunities in selective hydrocarbon functionalization. Many candidate materials have been prepared and in some cases high-valent species supported within these frameworks have been characterized. Because catalysis is fundamentally a kinetic phenomenon, characterization of potential reactive intermediates is insufficient to establishing the role of those intermediates in substrate functionalization. Catalysis is a kinetic phenomenon that fundamentally relies on stabilization of the turnover-limiting transition state, and thus kinetics experiments that report on the structure of the turnover limiting transition state are critical to studying catalytic reactions. Kinetic isotope effects, which report on the extent of bond-breaking or -making in the turnover-limiting transition state, and olefin functionalization diastereoselectivity, which is sensitive to the intimate mechanism of substrate oxidation, are simple probes of the origin of activity in apparent MOF-catalyzed reactions. Here 
we have advanced simple kinetic probes based on analysis of kinetic isotope effects and olefin epoxidation diastereoselectivity that represent powerful tools in evaluating the role of MOFs in catalysis. These experiments have indicated that MIL-125- $\mathrm{Cu}_{2} \mathrm{O}_{2}$ is not a catalyst for aerobic oxidation while the Fe-MOF-74 materials are bona fide catalysts for substrate functionalization. Similar to classic experiments that have been advanced to differentiate homo- and heterogeneous catalysis, the presented kinetic experiments should be a standard part of developing and evaluating new porous materials catalysts.

\section{Acknowledgement}

The authors acknowledge the U.S. Department of Energy (DOE), Office of Science, Office of Basic Energy Sciences, Catalysis Program (DE-SC0018977), the Welch Foundation (A-1907), and an Alfred P. Sloan Fellowship to DCP for financial support.

\section{References}

(1) (a) Cavani, F.; Teles, J. H. Sustainability in Catalytic Oxidation: An Alternative Approach or a Structural Evolution? ChemSusChem 2009, 2, 508-534. (b) Denisov, E. T.; Mitskevich, N. I.; Agabekov, V. E. LiquidPhase Oxidation of Oxygen-Containing Compound, Consultants Bureau, Planum Publishing: New York, 1977.

(2) (a) Lee, J.; Farha, O. K.; Roberts, J.; Scheidt, K. A.; Nguyen, S.; Hupp, J. T. Metal-Organic Framework Materials as Catalysts. Chem. Soc. Rev. 2009, 38, 1450-1459. (b) Leus, K.; Liu, Y.-Y.; Van Der Voort, P. Metal-Organic Frameworks as Selective or Chiral Oxidation Catalysts. Catal. Rev. 2014, 56, 1-56. (c) Wang, Q.; Astruc, D. State of the Art and Prospects in Metal-Organic Framework (MOF)-Based and MOF-Derived Nanocatalysis. Chem. Rev. 2020, 120, 1438-1511. (d) Liu, J.; Chen, L.; Cui, H.; Zhang, J.; Zhang, L.; Su, C.Y. Applications of Metal-Organic Frameworks in Heterogeneous Supramolecular Catalysis. Chem. Soc. Rev. 2014, 43, 6011-6061. (e) Corma, A.; Garcia, H.; Llabres i Xamena, F. X. Engineering' Metal Organic Frameworks for Heterogeneous Catalysis. Chem. Rev. 2010, 110, 4606-4655. (f) Chughtai, A. H.; Ahmad, N.; Younus, H. A.; Laypkov, A.; Verpoort, F. Metal-Organic Frameworks: Versatile Heterogeneous Catalysts for Efficient Catalytic Organic Transformations. Chem. Soc. Rev. 2015, 44, 6804-6849. (g) Ma, L.; Abney, C.; Lin, W. Enantioselective Catalysis with Homochiral Metal-Organic Frameworks. Chem. Soc. Rev. 2009, 38, 1248-1256. (h) Gascon, J.; Corma, A.; Kaptejin, F.; Llabres i Xamena, F. X.' Metal Organic Framework Catalysis: Quo Vadis? ACS Catal. 2014, 4, 361-378.

(3) (a) Chen, Y.; Ma, S. Biomimetic Catalysis of Metal-Organic Frameworks. Dalton Trans. 2016, 45, 97449753. (b) Thompson, Z.; Cowan, J. A. Artificial Metalloenzymes: Recent Developments and Innovations in Bioinorganic Catalysis. Small 2020, 16, 2000392. (c) Bour, J. R.; Wright, A. M.; He, X.; Dinca, M. Bioinspired Chemistry at MOF Secondary Building Units. 2020, 11, 1728-1737. (d) Chen, K.; Wu, C.-D. Designed Fabrication of Biomimetic Metal-Organic Frameworks for Catalytic Applications. Coord. Chem. Rev. 2019, 378, 445-465. (e) Rogge, S. M. J.; Bavykina, A.; Hajek, J.; Garcia, H.; Olivos-Suarez, A. I.; SepúlvedaEscribano, A.; Vimont, A.; Clet, G.; Bazin, P.; Kapteijn, F.; Daturi, M.; Ramos-Fernandez, E. V.; Llabrés I 
Xamena, F. X.; Van Speybroeck, V.; Gascon, J. Metal-Organic and Covalent Organic Frameworks as SingleSite Catalysts. Chem. Soc. Rev. 2017, 46, 3134-3184.

(4) For example, few studies evaluate mass transport barriers to MOF catalysis. See, Gao, W.-Y.; Cardenal, A. D.; Wang, C.-H.; Powers, D. C. In Operando Analysis of Diffusion in Porous Metal-Organic Framework Catalysts. Chem. Eur. J. 2019, 25, 3465-3476.

(5) (a) Widegren, J. A.; Finke, R. G. A Review of the Problem of Distinguishing True Homogeneous Catalysis from Soluble or Other Metal-Particle Heterogeneous Catalysis Under Reducing Conditions. J. Mol. Catal. A 2003, 198, 317-341. (b) Crabtree, R. H. Resolving Heterogeneity Problems and Impurity Artifacts in Operationally Homogeneous Transition Metal Catalysts. Chem. Rev. 2012, 112, 1536-1554. (c) Stracke, J. J.; Finke, R. G. Distinguishing Homogeneous from Heterogeneous Catalysis when Beginning with Polyoxometalates. ACS Catal. 2014, 4, 909-933. (d) Gärtner, D; Sandl, S; Wangelin, A. J. V. Homogeneous vs. heterogeneous: mechanistic insights into iron group metal-catalyzed reductions from poisoning experiments. Catal. Sci. Technol. 2020, 10, 3502-3514. (e) Artero, V.; Fontecave, M. Solar Fuels Generation and Molecular Systems: Is it Homogeneous or Heterogeneous Catalysis? Chem. Soc. Rev. 2013, 42, 23382356.

(6) (a) Phan, N. T. S.; Van Der Sluys, M.; Jones, C. W. On the Nature of the Active Species in Palladium Catalyzed Mizoroki-Heck and Suzuki-Miyaura Couplings - Homogeneous or Heterogeneous Catalysis, A Critical Review. Adv. Synth. Catal. 2006, 348, 609-679. (b) Balanta, A.; Godard, C.; Claver, C. Pd Nanoparticles for C-C Coupling Reactions. Chem. Soc. Rev. 2011, 40, 4973-4985. (c) Deraedt, C.; Astruc, D. "Homeopathic" Palladium Nanoparticle Catalysis of Cross Carbon-Carbon Coupling Reactions. Acc. Chem. Res. 2014, 47, 494-503.

(7) Paal, C.; Hartmann, W. Über den Einfluß von Fremdstoffen auf die Aktivitat der Katalysatoren. IV. Versuche mit Palladiumhydrosol in Qegenwart von Queksilber und Quecksilberoxyd. Ber. Deutsch. Ber. Dtsch. Chem. Ges. 1918, 51, 711-737.

(8) For limitations of the Hg-drop analysis, see: Gorunova, O. N.; Novitskiy, I. M.; Grishin, Y. K.; Gloriozov, I. P.; Roznyatovsky, V. A.; Khrustalev, V. N.; Kochetkov, K. A.; Dunina, V. V. When Applying the Mercury Poisoning Test to Palladacycle-Catalyzed Reactions, One Should Not Consider the Common Misconception of Mercury(0) Selectivity. Organometallics 2018, 37, 2842-2858.

(9) (a) Wang, C.-H.; Das, A.; Gao, W.-Y.; Powers, D. C. Probing Substrate Diffusion in Interstitial MOF Chemistry with Kinetic Isotope Effects. Angew. Chem. Int. Ed. 2018, 57, 3676-3681. (b) Wang, C.-H.; Gao, W.-Y.; Powers, D. C. Measuring and Modulating Substrate Confinement during Nitrogen-Atom Transfer in a Ru2-Based Metal-Organic Framework. J. Am. Chem. Soc. 2019, 141, 19203-19207.

(10) Feng, X.; Song, Y.; Chen, J. S.; Xu, Z.; Dunn, S. J.; Lin, W. Rational Construction of an Artificial Binuclear Copper Monooxygenase in a Metal-Organic Framework. J. Am. Chem. Soc. 2021, 143, 1107-1118.

(11) Balasubramanian, R.; Rosenzweig, A. C. Structural and Mechanistic Insights into Methane Oxidation by Particulate Methane Monooxygenase. Acc. Chem. Res. 2007, 40, 573-580.

(12) Kubacka, A.; Wang, Z.; Sulikowski, B.; Cortés Corberán, V. Hydroxylation/oxidation of benzene over CuZSM-5 systems: Optimization of the one-step route to phenol. J. Catal 2007, 250, 184-189.

(13) (a) Maity, A.; Hyun, S.-M.; Powers, D. C. Oxidase Catalysis via Aerobically Generated Hypervalent Iodine Intermediates. Nat. Chem. 2018, 10, 200-204. (b) Maity, A.; Hyun, S.-M.; Wortman, A. K.; Powers, D. C. Oxidation Catalysis by an Aerobically Generated Dess-Martin Periodinane Analogue. Angew. Chem. Int. Ed. 2018, 57, 7205-7209. (c) Hyun, S-M.; Yuan, M.; Maity, A.; Gutierrez, O.; Powers, D. C. The Role of Iodanyl Radicals as Critical Chain Carriers in Aerobic Hypervalent Iodine Chemistry. Chem 2019, 5, 2388-2404. (d) Miyamoto, K.; Yamashita, J.; Narita, S.; Sakai, Y.; Hirano, K.; Saito, T.; Wang, C.; Ochiai, M.; Uchiyama, M. Iodoarene-catalyzed oxidative transformations using molecular oxygen. Chem. Commun. 2017, 53, 97819784.

(14) Reich, L.; Stivala, S. S. Autoxidation of Hydrocarbons and Polyolefins: Kinetics and Mechanism, Marcel Dekker, Inc.: New York, 1969.

(15) For C-H oxygenation, see (a) Hammond, C. J.; Smith, J. R. L.; Nagatomi, E.; Stark, M. S.; Waddington, D. J. A Mechanistic Study of the Liquid Phase Autoxidation of Nonan-5-one. New. J. Chem. 2006, 30, 741-750. (b) Das, P.; Saha, D.; Saha, D.; Guin, J. Aerobic Direct C(sp2)-H Hydroxylation of 2-Arylpyridines by Palladium Catalysis Induced with Aldehyde Auto-Oxidation. ACS Catal. 2016, 6, 6050-6054.

(16) For olefin epoxidation chemistry, see: (a) Genêt, J. P.; Uziel, J.; Port, M.; Touzin, A. M.; Roland, S.; Thorimbert, S.; Tanier, S. A practical synthesis of $\alpha$-aminophosphonic acids. Tetrahedron Lett. 1992, 33, 7780. (b) Lassila, K. R.; Waller, F. J.; Werkheiser, S. E.; Wressell, A. L. Aldehyde/olefin cooxidations: Parallel epoxidation pathways and concerted decomposition of the peroxyacyl-olefin adduct. Tetrahedron Lett. 1994, 
35, 8077-8080. (c) Wentzel, B. B.; Alsters, P. L.; Feiters, M. C.; Nolte, R. J. M. Mechanistic Studies on the Mukaiyama Epoxidation. J. Org. Chem. 2004, 69, 3453-3464. (d) Jarboe, S. G.; Beak, P. Mechanism of Oxygen Transfer in the Epoxidation of an Olefin by Molecular Oxygen in the Presence of an Aldehyde. Org. Lett. 2000, 2, 357-360.

(17) (a) Ingold, K. U. Peroxy radicals. Acc. Chem. Res. 1969, 2, 1-9. (b) Howard, J. A.; Ingold, K. U.; Symonds, M. Absolute rate constants for hydrocarbon oxidation. VIII. The reactions of cumylperoxy radicals. Can. J. Chem. 1968, 46, 1017-1022. (c) Muchalski, H., Levonyak, A. J., Xu, L., Ingold, K. U., and Porter, N. A. Competition H(D) Kinetic Isotope Effects in the Autoxidation of Hydrocarbons. J. Am. Chem. Soc. 2015, 137, 94-97.

(18) (a) Larkin, D. R. The role of catalysts in the air oxidation of aliphatic aldehydes. J. Org. Chem. 1990, 55, 1563-1568. (b) Lehtinen, C.; Brunow, G. Factors Affecting the Selectivity of Air Oxidation Of 2-Ethyhexanal, an $\alpha$-Branched Aliphatic Aldehyde. Org. Proc. Res. Dev. 2000, 4, 544-549.

(19) (a) Wang, C.; Ren, X.-R.; Qi, C.-Z.; Yu, H.-Z. Mechanistic Study on Gold-Catalyzed Highly Selective Hydroamination of Alkylidenecyclopropanes. J. Org. Chem. 2016, 81, 7326-7335. (b) Kennedy, C. R.; Zhong, H.; Macaulay, R. L.; Chirik, P. J. Regio- and Diastereoselective Iron-Catalyzed [4+4]-Cycloaddition of 1,3-Dienes. J. Am. Chem. Soc. 2019, 141, 8557-8573. (c) Zheng, S.; Zhang, S.-Q.; Saeednia, B.; Zhou, J.; Anna, J. M.; Hong, X.; Molander, G. A. Diastereoselective olefin amidoacylation via photoredox PCET/nickel-dual catalysis: reaction scope and mechanistic insights. Chem. Sci. 2020, 11, 4131-4137.

(20) (a) Mizuno, N.; Weiner, H.; Finke, R. G. J. Mol. Catal. A 1996, 114, 15-28. (b) Nam, W.; Kim, H. J.; Kim, S. H.; Ho, R. Y. N.; Valentine, J. S. Inorg. Chem. 1996, 35, 1045-1049.

(21) (a) Xiao, D. J.; Bloch, E. D.; Mason, J. A.; Queen, W. L.; Hudson, M. R.; Planas, N.; Borycz, J.; Dzubak, A. L.; Verma, P.; Lee, K.; Bonino, F.; Crocellà, V.; Yano, J.; Bordiga, S.; Truhlar, D. G.; Gagliardi, L.; Brown, C. M.; Long, J. R. Oxidatoin of Ethane to Ethanol by $\mathrm{N}_{2} \mathrm{O}$ in a Metal-Organic Framework with Coordinatively Unsaturated Iron(II) Sites. Nat. Chem. 2014, 6, 590-595. (b) Verma, P.; Vogiatzis, K. D.; Planas, N.; Borycz, J.; Xiao, D. J.; Long, J. R.; Gagliardi, L.; Truhlar, D. G. Mechanism of Oxidation of Ethane to Ethanol at Iron(IV)-Oxo Sites in Magnesium-Diluted $\mathrm{Fe}_{2}$ (dobdc). J. Am. Chem. Soc. 2015, 137, 5770-5781.

(22) APCI-MS analysis of alcohol 5 leads to the observation of $\mathrm{m} / \mathrm{z}$ signals corresponding to 1,2dihydronaphthalene, the product of elimination from $\mathbf{5}$. The same signals were observed during APCI-MS analysis of a commercial sample of $\mathbf{5}$, which demonstrates that elimination to the corresponding olefin proceeds during MS analysis.

(23) Simmons, E. M.; Hartwig, J. F. On the Interpretation of Deuterium Kinetic Isotope Effects in C-H Bond Functionalizations by Transition-Metal Complexes. Angew. Chem. Int. Ed. 2012, 51, 3066-3072. 